07

\title{
Наносекундная динамика разрушения поверхностного слоя гетерогенного нанокристаллического тела (песчаника) при трении
}

\author{
() В.И. Веттегрень ${ }^{1}$, Г.А. Соболев ${ }^{2}$, А.В. Пономарев ${ }^{2}$, И.П. Щербаков ${ }^{1}$, Р.И. Мамалимов ${ }^{1}$ \\ ${ }^{1}$ Физико-технический институт им. А.Ф. Иофрфе РАН, \\ Санкт-Петербург, Россия \\ ${ }^{2}$ Институт фризики Земли им. О.Ю. Шмидта РАН, \\ Москва, Россия \\ E-mail: Victor.Vettegren@mail.ioffe.ru
}

(Поступила в Редакцию 10 октября 2016 г.)

\begin{abstract}
Обнаружено, что при трении гетерогенного материала - песчаника - возникает триболюминесценция. Она соответствует свечению свободных радикалов $\equiv \mathrm{Si}-\mathrm{O}$ и ионов $\mathrm{Fe}^{3+}$. Эти радикалы и ионы образуются при разрываx SiOSi связей в нанокристаллах кварца и полевого шпата, входящих в состав песчаника. Временна́я зависимость TL представляет собой набор вспышек, длительность каждой из них составляет несколько ns. Предполагается, что вспышки соответствуют трещинам. Оценена величина раскрытия трещин — $180 \mathrm{~nm}$. Распределение трещин по размерам экспоненциальное.
\end{abstract}

Работа выполнена при финансовой поддержке Российского фонда фундаментальных исследований (грант № 16-05-00137).

DOI: 10.21883/FTT.2017.05.44382.373

\section{1. Введение}

Согласно современным представлениям, в основе механизма землетрясений лежит неустойчивость скольжения земных плит. Она может быть порождена резкими изменениями коэффициента трения на контактах пород $[1,2]$. В результате изнашивания поверхности контактирующих пород часто сглаживаются и образуются, так называемые, „зеркала скольжения“, коэффициент трения которых на порядок меньше, чем подстилающей породы. Механизм образования таких зеркал до сих пор неизвестен $[3,4]$.

Первое экспериментальное исследование строения природного зеркала скольжения на поверхности песчаника, было проведено в работе [5]. Анализ данных инфракрасной и рамановской спектроскопии показал, что зеркало скольжения состоит из деформированных нанокристаллов монтмориллонита и анатаза. Порода под зеркалом содержит кристаллы кварца, полевого шпата, монтмориллонита и анатаза.

В [6] методами оптической микроскопии, фотолюминесцентной (PL) и рамановской спектроскопии исследовано строение поверхностного слоя толщиной $\sim 30 \mathrm{~nm}$ песчаника, смоченного водой. Обнаружено, что до трения они содержали кристаллы кварца, полевого шпата, монтмориллонита и анатаза с линейными размерами от нескольких десятков $\mu \mathrm{m}$ до $1 \mathrm{~mm}$. Кристаллы этих минералов состояли из зерен, линейный размер которых составляет 8-15 nm. Зерна содержали большое количество дефектов: вакансий, самозахваченных экситонов, примесных ионов и т.п. Трение вызвало уменьшение размеров кристаллов кварца, по крайней мере, на два порядка. Концентрация кварца и полевого шпата уменьшилась более чем в 5 раз. Это явление могло быть вызвано разрушением кристаллических решеток этих минералов.

Цель настоящей работы - обнаружить свободные радикалы $\equiv \mathrm{Si}-\mathrm{O}$, образующиеся при разрывах $\mathrm{Si}-\mathrm{O}-\mathrm{Si}$ связей в кристаллических решетках кварца и полевого шпата и исследовать динамику их накопления.

Для ее достижения было использовано явление триболюминесценции (TL). Предполагалось, что появляющиеся свободные радикалы могут находиться в возбужденном состоянии. Релаксация возбуждения приведет к появлению TL. Анализ спектров TL может позволить определить какие химические связи разрываются, а исследование изменения интенсивности TL во времени исследовать динамику накопления разрывов.

\section{2. Объект и методы исследования}

Для решения задачи была создана установка, состоящая из вращающегося диска и стержня, вырезанных из песчаника (рис. 1). Линейная скорость вращения диска $v_{d}=26 \mathrm{~m} / \mathrm{s}$. Песчаник добывался из шурфов полуострова Средний на северном побережье Кольского полуострова.

Спектры TL регистрировали с помощью оптоволоконного спектрометра AvaSpecULSi2048L-USB2 OE.

Чтобы исследовать динамику разрушения песчаника, излучение, возникающее при трении, кварцевым световодом подавалось на поверхность фотоэлектронного умножителя РЕМ 136, а с него - на вход аналоговоцифрового преобразователя ADS3112. Там он оцифровывался и с временным разрешением $2 \mathrm{~ns}$ записывался в память компьютера для дальнейшей обработки и хранения. 


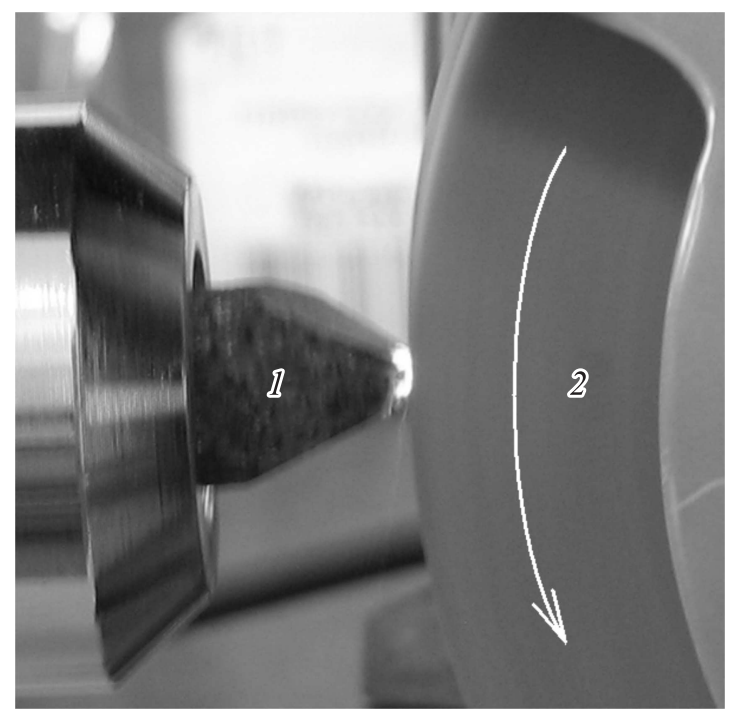

Рис. 1. Фрагмент установки для исследования механизма разрушения песчаника при трении: 1 - стержень, 2 - диск. Яркое пятно между стержнем и диском - излучение при трении.

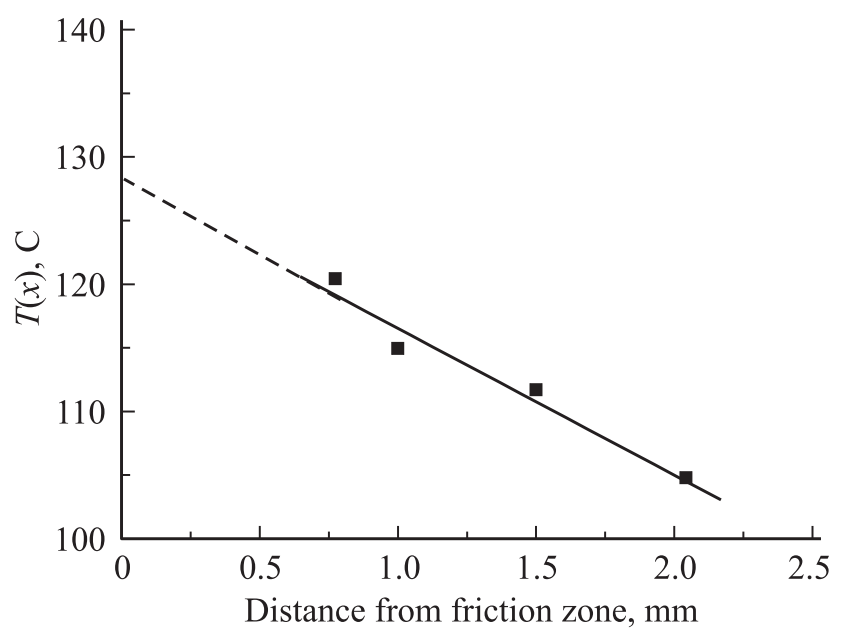

Рис. 2. Зависимость температуры $T(x)$ стержня от расстояния $x$ до зоны трения.

При трении диск и стержень нагреваются. Чтобы оценить температуру в зоне трения, вдоль оси стержня был пропилен паз глубиной $\sim 1 \mathrm{~mm}$ и в него вставлена термопара. Перемещая термопару внутри паза, измеряли температуру стержня $T(x)$ на различных расстояниях $x$ от зоны трения.

В стационарных условиях температура $T(x)$, связана с температурой $T(0)$ в зоне трения выражением (уравнение Пуассона) [7]:

$$
T(x)=T(0)-\frac{F(x)}{\lambda} x,
$$

где $F(x)$ - плотность теплового источника, а $\lambda-$ коэффициент теплопроводности. В соответствии с этим уравнением, зависимость температуры от расстояния оказалась близкой к линейной (рис. 2). Экстраполируя ее к $x=0$, нашли температуру в зоне трения $-\sim 130 \mathrm{C}$.

\section{3. Спектр TL, возникающий при трении песчаника}

Спектр излучения при трении (рис. 3,a) образуется при наложении друг на друга спектров теплового излучения и TL. Чтобы выделить спектр TL, диск нагревали до $130 \mathrm{C}$, записывали спектр его теплового излучения и вычитали его из спектра, полученного при трении.

Полученный таким образом максимум TL (рис. $3, b$ ) представляет собой сумму 2 ,элементарных“ полос, имеющих гауссову форму [8]. Первая - с максимумом $\sim 1.91 \mathrm{eV}$ - приписана возбужденным свободным радикалам $\equiv \mathrm{Si}-\mathrm{O}$ в кварце и полевом шпате [9-12]. Эти радикалы образуются при разрывах химических связей $\mathrm{Si}-\mathrm{O}-\mathrm{Si}$ в кристаллических решетках кварца и полевого шпата. Максимум $\sim 1.65 \mathrm{eV}$ приписан возбужденным ионам $\mathrm{Fe}^{3+}$ в полевом шпате [13], энергия которым передается от радикалов $\equiv \mathrm{Si}-\mathrm{O}[8]$. Следовательно, об-
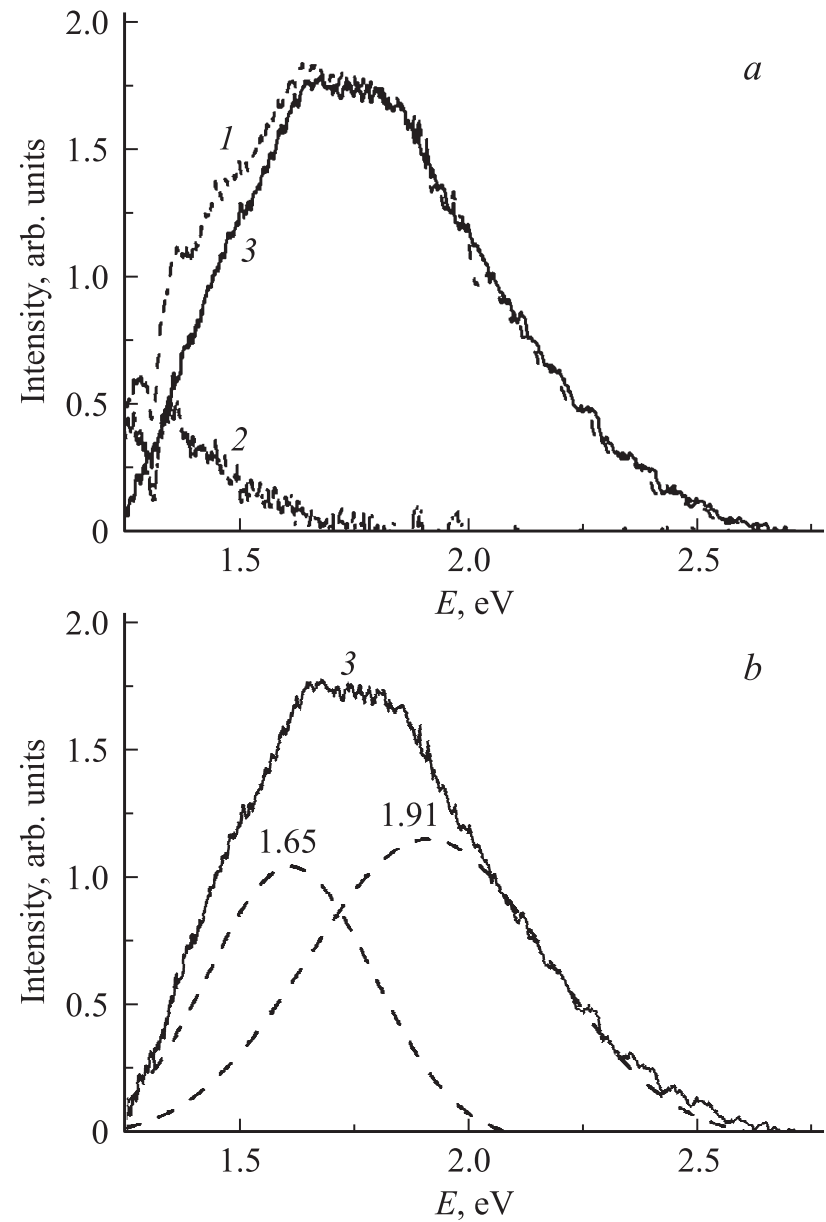

Рис. 3. Спектры излучения при трении песчаника: 1 измеренный, 2 - тепловое излучение, 3 - TL. Штриховыми линиями показаны максимумы, соответствующие люминесценции свободных радикалов $\equiv \mathrm{Si}-\mathrm{O}$ и ионов $\mathrm{Fe}^{3+}$. 
наруженное уменьшение концентрации нанокристаллов кварца и полевого шпата в поверхностном слое песчаника при трении действительно вызвано разрушением их кристаллических решеток.

\section{4. Динамика TL}

Фрагмент временно́й зависимости интенсивности TL показан на рис. 4. Она представляет собой набор вспышек, интенсивность которых варьирует, по крайней меpe, на порядок, а временной интервал между ними - от нескольких ns до $\sim 1 \mu \mathrm{s}$.

Вспышки, как правило, состоят из 5-6 максимумов (рис. 5), наложенных друг на друга, что искажает их форму.

Проведенный анализ позволил найти вспышки, один из максимумов которых был в наименьшей степени искажен из-за наложения соседних. Он показан на рис. 6. Его интенсивность пропорциональна числу возбужденных свободных радикалов и ионов. Форма максимума задана скоростями образования и дезактивации радикалов и

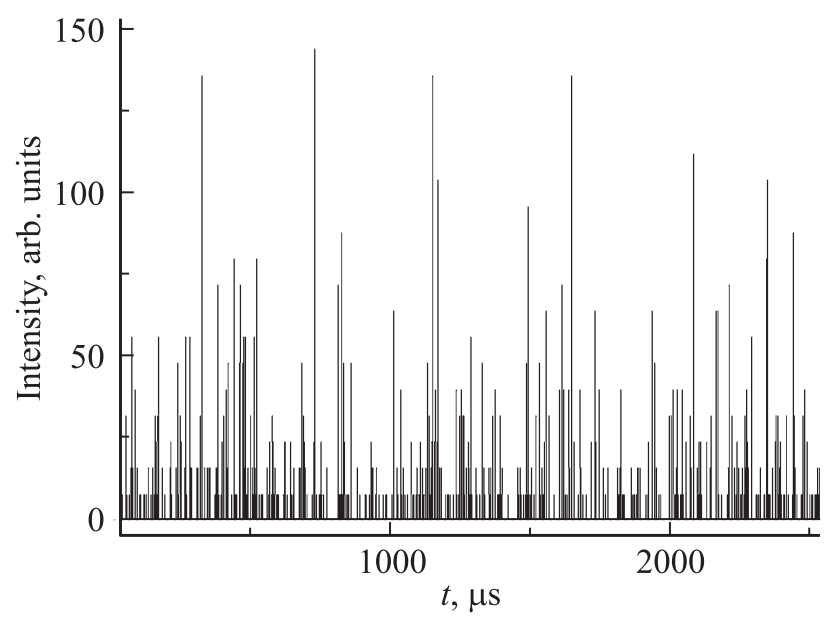

Рис. 4. Временна́я зависимость интенсивности TL.

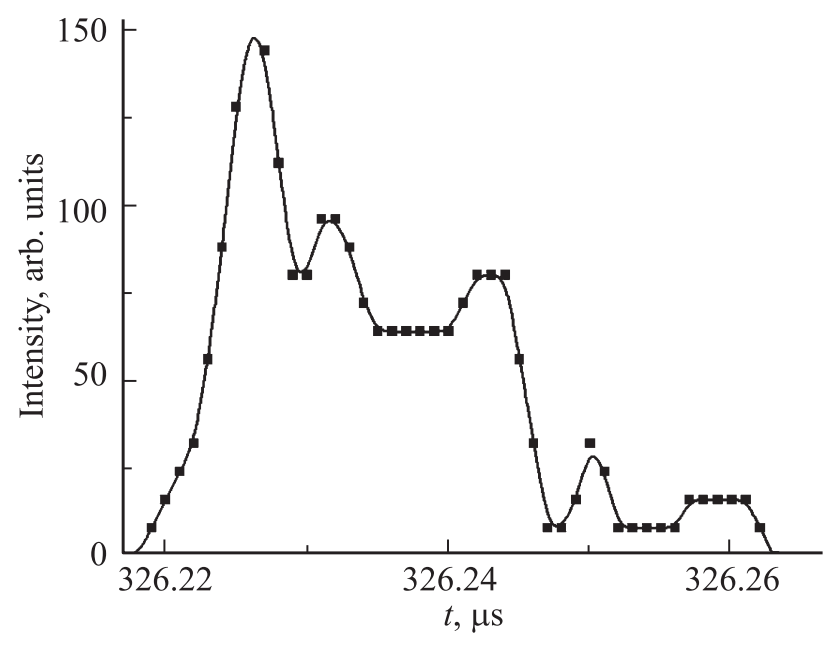

Рис. 5. Вспышка TL.

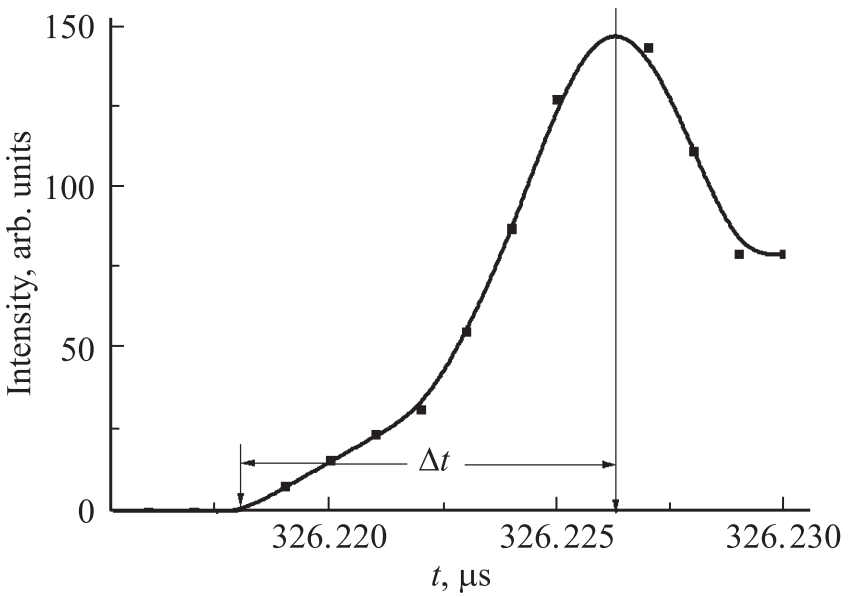

Рис. 6. Одиночный максимум TL.

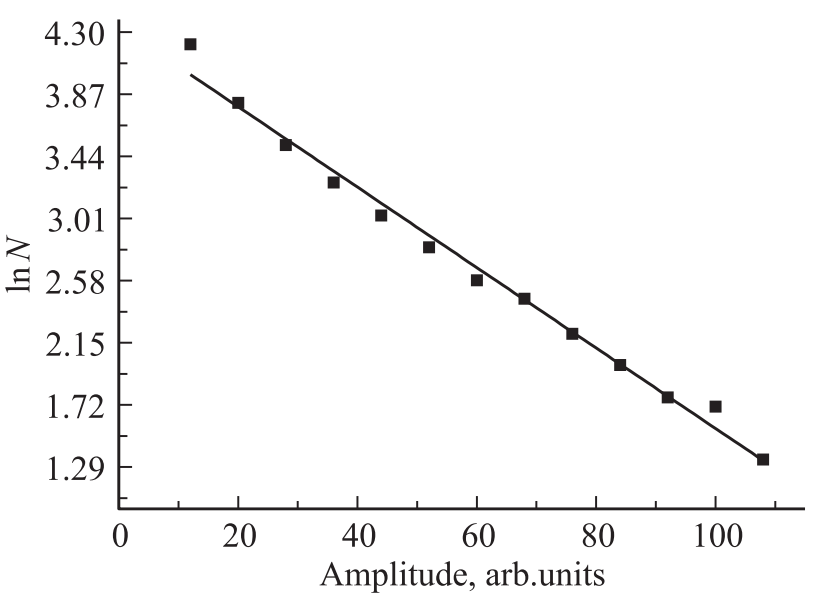

Рис. 7. Распределение амплитуд вспышек TL.

ионов, а также - скоростью уменьшения сигнала от РЕМ после прекращения свечения (определяемой величинами паразитной емкости и сопротивления нагрузки). Вначале число возбужденных радикалов и ионов мало, и скоростью их дезактивации можно пренебречь. В этом случае, как видно из рис. 6, число возбужденных свободных радикалов и ионов растет приблизительно экспоненциально от времени. Такой вид зависимости скорости накопления радикалов согласуется с представлением о том, что она задана вероятностью образования термических разрушающих флуктуаций $[14,15]$.

Появление максимума, по-видимому, соответствует рождению трещины [12]. Тогда из рассмотрения рис. 6 следует, что скорость роста трещины вначале растет, достигает максимального значения, а затем трещина останавливается. Временной интервал $\Delta t$ на рис. 6 между моментами появления и достижения максимального значения TL приблизительно соответствует времени раскрытия трещины. Оказалось, что для различных максимумов среднее значение $\Delta t \approx 7 \mathrm{~ns}$. Поэтому средняя величина раскрытия трещин $v_{d} \Delta t=26 \cdot 7 \approx 180 \mathrm{~nm}$, что, по крайней мере, на порядок меньше размеров кристал- 
лов кварца (от $\sim 1 \mu \mathrm{m}$ до $\sim 1 \mathrm{~mm}[6]$ ), но на порядок больше линейных размеров зерен $(8-15 \mathrm{~nm} \mathrm{[6]).} \mathrm{Это}$ показывает, что при образовании трещины разрушается около $10^{2}$ зерен кварца и полевого шпата.

Распределение числа $N$ вспышек TL экспоненциальное (рис. 7). В [16] установлено, что такое распределение характерно для случая, когда трещины в теле накапливаются делокализовано. По-видимому, делокализация обусловлена беспорядочным расположением кристаллов кварца и полевого шпата в исследованных образцах песчаника.

\section{5. Заключение}

При трении песчаника $\mathrm{Si}-\mathrm{O}-\mathrm{Si}$ связи в кристаллических решетках нанокристаллов кварца и полевого шпата разрываются. После их разрыва образуются возбужденные свободные радикалы $\equiv \mathrm{Si}-\mathrm{O}$ и ионы $\mathrm{Fe}^{3+}$. При релаксации возбуждения возникают вспышки TL. Вспышки соответствуют появлению трещин. Временной интервал между появлением трещин варьирует от нескольких ns до $1 \mu \mathrm{s}$, а их размеры изменяются на порядок. Величина раскрытия трещин - $180 \mathrm{~nm}$.

\section{Список литературы}

[1] J.H. Dietrich. J. Geophys. Res. 77, 3690 (1972).

[2] C.H. Scholz. The mechanics of earthquakes and faulting. $2^{\text {nd }}$ ed. Cambridge University Press, Cambridge. (2002). $471 \mathrm{p}$.

[3] G. Di Toro, R. Han, T. Hirose, N. De Paola, S. Nielsen, K. Mizoguchi, F. Ferri, M. Cocco, T. Shimamoto. Nature 471, 494 (2011).

[4] A. Niemeijer, G. Di Toro, W.A. Griffith, A. Bistacchi, S.A.F. Smith, S. Nielsen. J. Struct. Geology 39, 2 (2012).

[5] Г.А. Соболев, С.М. Киреенкова, Ю.А. Морозов, А.И. Смульская, В.И. Веттегрень, В.Б. Кулик, Р.И. Мамалимов. Физика Земли 9-10, 17 (2012).

[6] В.И. Веттегрень, А.В. Пономарев, Г.А. Соболев, И.П. Щербаков, Р.И. Мамалимов, В.Б. Кулик, А.В. Патонин. ФТТ 59, 569 (2017).

[7] Л.Д. Ландау, Е.М. Лифшиц. Теоретическая физика. Т. 5. Статистическая физика. Ч. 1. М. Наука. (1976). 584 с.

[8] N.J. Turro. Modern Molecular Photochemistry. University Sci. Press, Columbia University. (1991). 628 p.

[9] G.N. Chapman, A.J. Walton. J. Appl. Phys. 54, 5961 (1983).

[10] А.Н. Стрелецкий, А.Б. Пакович, И.Ю. Бутягин. Изв. АН CCCP 50, 3, 477 (1986).

[11] Y. Kawaguchi. Jpn. J. Appl. Phys. 37, 1892 (1998).

[12] В.И. Веттегрень, А.Я. Башкарев, Р.И. Мамалимов, И.П. Щербаков. ФТТ 50, 29 (2008).

[13] M.R. Krbetschek, J. Götze, G. Irmer, U. Rieser, T. Trautmann. Mineral Petrol. 76, 167 (2002).

[14] В.Р. Регель, А.И. Слуцкер, Э.Е. Томашевский. Кинетическая природа прочности твердых тел. Наука, М. (1974). $560 \mathrm{c}$.

[15] В.А. Петров, А.Я Башкарев., В.И Веттегрень. Физические основы прогнозирования долговечности конструкционных материалов. Политехника, СПб. (1993). 475 с.

[16] Е.Е. Дамаскинская, А.Г. Кадомцев. Письма в ЖТФ 39, 2 , 29 (2013) 